confused with those of the eye, ear, nose and rectum, as well as of the vagina and uterus, but the present purpose is chiefly to call attention to the fact that this habit of the muscles of the jaws is of extremely common occurrence-in fact, nearly always an active feature of nervous states-for if caused, as sometimes happens, by overstimulus of the centers controlling those muscles, the result of some etiologic excitement elsewhere, then the effect is simply to inorease the severity of symptoms; on the other hand, it may be the irritant, and solely responsible, but in either case the simple attention necessary to correction of the difficulty is a matter of first necessity in the treatment of a large majority of sufferers from functional and other disorders of the nervous system.

\section{NERVOUSNESS AN ELEMENT IN HYPERPYREXIA.}

Presented to the Section on Neurology and Medical Jurisprudence, at the Forty-ninth Annual Meeting of the American Medical Association, held at Denver, Colo., June 7-10, 1898. BY C. C. HERSMAN, M.D.

Lecturer on Mental and Nervous Diseases, Western University of Penn sylvania, Medical Department; Physician to St. Francis Hospi-

tal, Insane Department; Alienist and Neurologist, South Side Hospital, Pittsburg. PITTSBURG, PA.

Temperature, from Hippocrates down, has been recognized as a factor in disease. In the present paper the topic is to be discussed with reference to the explosive (nerve-storm-like) and sudden elevation of temperature under certain mental impressions or conditions.

Musser attributes the stability of temperature to the central regulating apparatus, called the thermotoxic apparatus. This aggregation of forces is under the control of the nervous system, either through the motor or special nerves which pass with them to and from definite centers in the brain, called heat centers. He claims that the elevation of temperature is due to the increased disintegration of nitrogenous tissue. It has also been said that the high range is caused by the taking in of more poison than is gotten rid of, or, to give bacteriologic zest to the expression, the microbes are in competition with the corpuscles of the blood.

High temperatures are not so dangerous, or so uniformly fatal, as low. Da Costa records a recovery from a temperature of $110 \mathrm{~F}$. in the axilla, following cerebral rheumatism. Teal reports a case of recovery from a spinal injury with a range of temperature of 112 to 114 F., which continued for days. Dr. J. B. Murdoch of Pittsburg, formerly Dean of the Medical Department of the Western University of Pennsylvania, admitted a case to the Western Pennslyvania Hospital Dec. 13, 1893, whose temperature on the eighth, ninth, tenth and eleventh days was respectively 112, 114.8, 119 and $120 \mathrm{~F}$. His patient had hysteric symptoms and he, with others of the staff who saw the case, decided that the hysteria was the cause of the high temperature. The cause of these high temperatures is mere conjecture. The increased disintegration of nitrogenous tissue and the microbes in competition with the blood corpuscles can not be relied on.

Experiments upon dogs have shown that to irritate certain centers of the brain will control temperature, while destruction of the center will cause a high rise. I have thought that a hyperesthetic condition of the heat center might answer for the cause, but according to the irritation theory, nothing short of a paralysis of the center could cause the rise, while the hyperesthesia would control it. In the following cases the last thing mentioned could be the only plausible one to me:

Case 1.-K. R., aged 21, American, nurse. Disease diagnosed as spinal meningitis. Admitted to South Side Hospital Dec. 4, 1897. Family history negative. Personal history, typhoid two or three years prior. During the course of the disease she complained severely of a pain in back of head. Delirium marked. Three months ago confined to bed with severe pain around cecum and caput coli, with some inflation. No elevation of temperature, but nervous, with inclination to hysteric aymptoms.

Present trouble began with severe headache, with boring pain in back of neck, followed by numerous chills and muscles of back of neck rigid, with head slightly drawn back, tendernese along spine and mild delirium. Retention of urine. At times evening temperature $107 \mathrm{~F}$., but was promptly reduced in a very few minutes with ice sponge. Antipyretics had little effect. Pulse at times very weak. On the seventh day the temperature was highest, $118 \mathrm{~F}$.

At times the temperature would drop from $110 \mathrm{~F}$. to normal in a very few (twenty) minutes without interference, but mostly the sponge bath was resorted to with very prompt effect. Usually when she had the high temperatures she had marked hysteric symptoms. The fever always abated most rapidly when treated by those in whom she had most faith and liked best. A visit from friends would provoke an attack, seemingly, to me, to show how sick she was.

My diagnosis differed from those who had preceded me, as I could see nothing but a very exaggerated nervous condition attended by hyperpyrexia and hysteric symptoms. At the end of fifteen days sho was sent home.

Case 2.-Lizzie N., aged 29, Irish, domestic. In United States eight years. Admitted to South Side Hospital of Pitteburg, Dec. 10, 1897, her disease having been diagnosed articular rheumatism of one week's duration, which was ushered in by a chill.

On admission temperature $99 \mathrm{~F}$., pulse 102, respiration 24. Joints sore and very tender, especially the knees. On the second day after admission the temperature became normal. On the fourth day $104 \mathrm{~F}$., eighth and ninth days normal. On the thirteenth day normal, but on the fourteenth it rose to 106.2, pulse 80 . On the eighteenth day 110.9 , pulse 80 ; twenty-third day $11: 30$ AM., 110, but at $2: 30$ P.M. had dropped to 99 , pulse 80. At various times from the eighteenth to the twenty-third day the thermometer registered 110.

On the thirty.fourth day of the disease the register was 112. On the thirty.fifth day at $11: 30 \mathrm{~A} . \mathrm{M}$. I took her temperature under the tongue at $116 \mathrm{~F}$. with a pulse of 80 and a cool skin, and twenty minutes after I left the ward it was registered at 102 by another thermometer. On the forty-second day after admiseion the thermometer registered 118.4. Her temperature for the past fow days ran along from 105 to 108 , occasionally down as low as 104 , and once to 103 . This continued up to the sixty-ninth day, when the temperature dropped to 99 , following a chill, but soon to return to its old haunts, 108 to 110 . This high range continued until the eighty-sixth day, when at $3: 20$ A.M. it registered 98 , but again went back to 107.4 , which continued until the ninety-third day, when she became dissatisfied and asked permission to leave the hospital, which was granted.

She left with a temperature of 104.8 and walked with slight assistance to the street-cars, three squares away, but on the evening of the same day she returned slightly intoxicated and asked to be readmitted. Her temperature was then 97.4. On the second day after readmission her temperature was 108, on the third 110 , on the fifth 112.4 , on the sixth, A.M. 97 , but at $1: 20$ P. M. was again at 111.2; on the seventh 97 , but on the eighth was 108, at which time she was sent out of the hospital, 101 days after her first admission.

She went to the home of her former employer, where she remained for about ten days, going about the house, and occasionally going out. On attempting to alight from a street-car she broke her ankle and was sent to a hospital. Her improvement has been continuous and her temperature has never been above 99.4 F. Usually it has been normal. In the first hospital her rest at night was very much broken. Sometimes she would sleep all night, at others lie awake until 3 or 4 o'clock in the morning. If the interne not in attendance on her would administer her hypnotic she would be likely to lie awake all night watching for "her doctor," to find out whether the 
medicine was correct. Seemingly, the hypnotic administered were completely overpowered (paralyzed), the radiaby the wrong person destroyed the hypnosis. If she were tion possibly interfered with, consequently the heat piqued or worried the temperature would rise. At times when storage. Specimen sections of temperature chart her temperature would be highest. These temperatures were give an idea of extreme fall and rise.

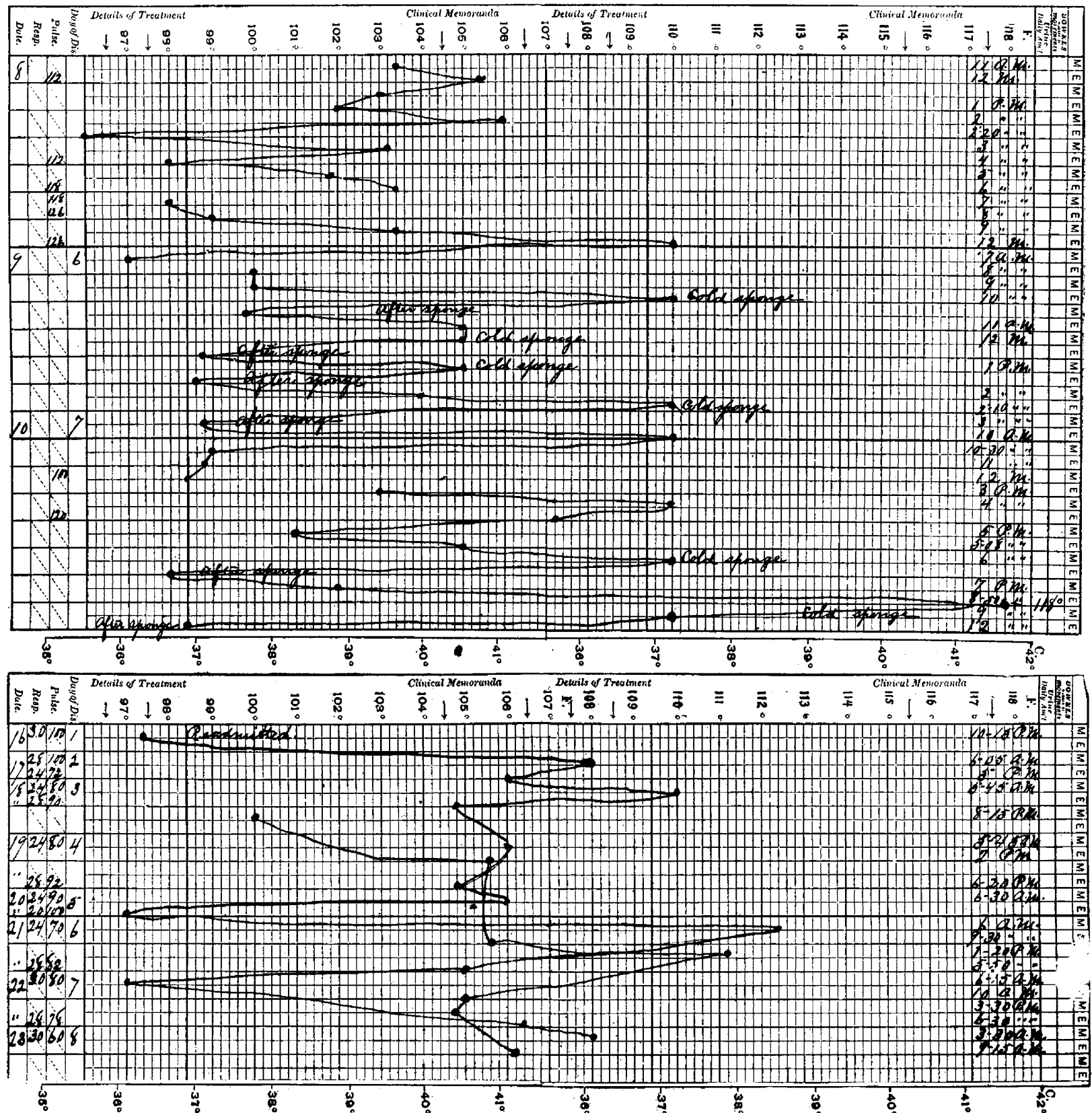

taken with both fever and bath thermometers, under the tongue, in the axilla and in the rectum.

During this period of hyperpyrexia she could sit up in bed, at times on a chair, and she always expressed herself as relieved and rested afterward. At times she was led about the room, which seemed to have more effect on her high temperature than drugs.

Like all the Celtic race, she was very much afraid of dying, and when most agitated her temperature was highest. After a talk with her, an examination, or a pretense to such, and an assurance that she was better, her temperature would usually lower. One nurse she disliked, and her presence would aggravate her fever.

\section{DISCORDANT SOUNDS A MENACE TO} NERVES.

Presented to the Section on Neurology and Medical Jurisprudence, at the Forty-ninth Annual Meeting of the American Medical Association, held at Denver, Colo., June 7-10, 1898.

BY JOSEPH A. GUTHRIE, M.D., P. A. SURGEON U. S. N. MEMBER OF THE ASSOCIATION OF MILITARY SURGEONS OF THE UNITED STATES, ETC.

The reason for selecting this subject is because of

Query: What was the disease in the two cases a number of inquiries made to me personally, regardreported? My diagnosis was hysteric hyperpyrexia. ing the why and the wherefores relative to it; and as. The tender joints in the one, and the tender spine in in some instances I was at a loss for ready answer, it the other, were hysteric symptoms, rather than rheu- behooved me to place my theme in the hands of those matic or meningitic. The emotional centers were so whose learning and experience I am sure will help me overburdened or exaggerated that the heat centers out of a quandary, rather than turn a critical eye upon 